\title{
Segurança na União Europeia e UNASUL: entre o institucionalismo e o cosmopolitismo
}

Security in the European Union and UNASUR: between institutionalism and cosmopolitism

\author{
Demetrius Cesário Pereira ${ }^{1}$ \\ Rafael Assumpção Rocha²
}

\section{RESUMO}

O presente artigo pretende analisar se a supranacionalização da UE e da UNASUL em termos políticos foi acompanhada de controles democráticos por meio de parlamentos regionais, na formulação e implementação da política de segurança de ambos os blocos. Para tal, utilizam-se as teorias institucionalistas e cosmopolitas, com suas visões de supranacionalidade $e$ democracia aplicadas às relações internacionais. Desse modo, primeiramente discute-se a escola liberal-institucionalista com seu conceito de supranacionalidade, seguido das aspirações democráticas do cosmopolitismo, para então aplicar tais teorizações à UE e à UNASUL. Com isso, corrobora-se a hipótese de que a UE seria mais supranacional e democrática que a UNASUL em termos de segurança.

Palavras-chave: UNASUL; União Europeia; segurança.

\section{ABSTRACT}

The present article intends to analyze if the supranationalization of the EU and UNASUR in political terms was accompanied of democratic controls, in the formulation and implementation of the security policy of both blocs. For this, it is used institutionalist and cosmopolitan theories, with theirs visions of supranationality and democracy applied to international relations. This way, firstly, it is discussed the liberal-institutionalist school with its concept of supranationality, followed by the democratic aspirations of cosmopolitism to then apply those theorizations to the EU and UNASUR. With this, the hypothesis that the EU would be more supranational and democratic than UNASUR in terms of security is reinforced.

Key-words: UNASUR; European Union; security.

\footnotetext{
1 Pós-doutorando em Ciência Política, UFPR, Curitiba, Brasil.

2 Doutorando em Relações Internacionais, IREL-Unb, Brasília, Brasil. 


\section{INTRODUÇ̃̃o}

0 presente trabalho ${ }^{3}$ visa analisar comparativamente a segurança regional na Europa e na América do Sul a partir de uma perspectiva institucional-cosmopolita, em que a supranacionalização deva ser acompanhada de controles democráticos. Parte-se da perspectiva normativa das relações internacionais ${ }^{4}$, sem, no entanto, negar a relevância e a atualidade das análises que se utilizam de teorias como o realismo ou que possuem como foco principal a geopolítica entre as nações ou entre as organizações. Busca-se uma análise complementar, ou, até mesmo, alternativa, das abordagens tradicionais sobre os estudos de defesa e segurança. ${ }^{5}$

Para isso, primeiramente, procura-se estabelecer os pontos de contato entre a visão institucionalista e a cosmopolita, esclarecendo-se concepções-chave dentro das duas perspectivas: supranacionalização e democracia, respectivamente. Estes conceitos podem levar a importantes perspectivas de médio e longo prazo sobre o comportamento das organizações internacionais, especialmente em áreas como defesa e segurança, consideradas primordiais para os Estados e por isso menos tendentes à supranacionalização e controles democráticos. As análises, no entanto, apesar de se distanciarem do positivismo puro (ou tradicional), não se aproximam do idealismo clássico. Considera-se que as abordagens teóricas aqui desenvolvidas podem ser propositivas, prospectando cenários possíveis, sem deixar de considerar as realidades materiais do presente.

\footnotetext{
${ }^{3}$ Desenvolvimento de artigo apresentando oralmente no VIII Encontro Nacional de Estudos de Defesa (2014).

${ }^{4} \mathrm{~A}$ teoria normativa aqui mencionada envolve todas as abordagens conceituas cujo foco principal é a análise dos valores e o estabelecimento de padrões de "conduta e recomendações de certos modos de vida e estruturas institucionais" (SÁ GUIMARÃES, 2008, p. 573). E ainda, de acordo com a definição de Chris Brown (1992, p. 3): "por teoria normativa nas relações internacionais se entende aqueles trabalhos que abordam a dimensão moral das relações internacionais e as questões mais amplas em significado e interpretação gerada pela disciplina. No sentido mais básico, aborda a natureza ética das relações entre as comunidades/estados".

${ }^{5}$ De acordo com Fernando de Sousa (2005, p. 60), "nas Relações Internacionais, o conceito de defesa tem estado tradicionalmente associado às áreas de segurança e militar, apontando para uma forma de proteger valores escassos de ataque" Já o conceito de segurança, refere-se à "ausência de ameaça, e a sua obtenção constitui um objetivo fundamental da política governamental". Complementarmente, o General Rui Monarca da Silveira $(2004,171)$, explica que "o conceito de segurança está associado a um estado de proteção e o conceito de defesa envolve ações, atitudes e medidas. Enquanto a defesa envolve medidas que incluem, prioritariamente, a aplicação direta do instrumento militar, estabelecidas com base em um quadro definido de ameaças, a segurança pode estar relacionada a uma série de ameaças não ortodoxas, para as quais não se aplica resposta militar tradicional, como, por exemplo, o crime organizado e a instabilidade política e social".
}

Conjuntura Global, vol. 4 n.3, set./dez., 2015, p. 438-456. 
A partir dessas duas concepções, os dois processos de integração serão abordados separadamente, primeiramente no âmbito da União Europeia (UE) e depois na União das Nações Sul-Americanas (UNASUL). Desse modo, verificar-se-á se a supranacionalização da segurança no âmbito regional, uma vez constatada, foi acompanhada de um controle democrático institucional. Por fim, comparam-se os dois processos de integração para confirmar a aproximação europeia do cosmopolitismo, no sentido de conciliar de maneira mais avançada a supranacionalização com a democracia em matéria de segurança e defesa. Já no caso sul-americano, espera-se um avanço menor em direção aos anseios institucionais e cosmopolitas.

\section{INSTITUCIONALISMO E SUPRANACIONALIDADE}

Sob a ótica do liberalismo institucional (ou internacionalismo liberal), durante a maior parte do século $\mathrm{XX}$, um elemento central na busca pela paz foi o respeito às regras do sistema de Westfália, posto que este sistema fosse uma condição fundamental para a evolução do Estado liberal. Estas regras incluem a não ingerência, igualdade jurídica, a reciprocidade, o respeito territorial e pela diversidade religiosa e política, entre outros (HOLSTI, 1999). Porém, no contexto internacional hostil, em que o estado de insegurança de um pode levar à insegurança de outros, o compromisso com a ideia hipotética de construção clássica da paz liberal tornou-se inviável, já que comprometeria o "jogo de soberania"6 nos termos de Westfália (JACKSON, 2007) e, assim, abriria uma "caixa de Pandora" de estratégias intervencionistas nas relações internacionais (LIDEN, 2006). No entanto, a era pós-Guerra Fria promoveu um reconhecimento crescente da mudança do papel do Estado numa época de globalização7, e acabou por mudar a concepção liberal internacionalista "clássico" sobre o jogo da soberania em uma direção ainda mais liberal, para não dizer cosmopolita. ${ }^{8}$

\footnotetext{
${ }^{6}$ Aqui, referimo-nos ao que Jackson classifica como o jogo clássico de soberania: a soberania era reconhecida às unidades políticas que logravam o efetivo controle territorial e a conformidade ao seu "padrão civilizatório".

${ }^{7}$ Neste contexto, a globalização é normalmente entendida como um processo de "integração econômica, política e social dos Estados e sociedades, tanto horizontais quanto verticalmente em teias concisas de interdependência". (GILEDITSCH; SOYSA, 2002).

${ }^{8}$ Segundo Nogueira e Messari, para o liberalismo institucional "a 'evolução' das relações internacionais não pode ser nada além da construção de instituições cada vez mais eficientes que viabilizem o crescimento do bem- 
A partir desta perspectiva, a sociedade internacional pode ser entendida como a estrutura de regras, normas e instituições produzidas pelas atividades em curso das pessoas que agem em nome de líderes políticos, ou seja, diplomatas e funcionários de outros Estados. Uma sociedade internacional é, portanto, qualitativamente diferente da noção de um sistema internacional no qual a interação entre os países do mundo é regulada pela estrutura anárquica do sistema e a distribuição de capacidades materiais dentro dele. ${ }^{9}$

Pode-se dizer que resumidamente o institucionalismo liberal possui três características essenciais: as instituições multilaterais que em conjunto com regimes internacionais normatizam a conduta externa dos Estados; a importância da boa-fé, da transparência discursiva e da ação democrática como prática aceita e amplamente debatida nos fóruns internacionais; e, por fim, esta abordagem teórica se fundamenta na necessidade de multilateralidade participativa dos Estados que estão posicionados em um patamar de isonomia e coordenação. Aqui, ressalta-se a crescente importância do papel das Organizações Internacionais (OIs) nas relações internacionais.

Postula-se, portanto, que as organizações internacionais passaram progressivamente a ocupar um lugar significativo na comunidade internacional, sem que isto tenha ultrapassado a importância dos próprios Estados. A consolidação das OIs no cenário internacional levou ao rompimento do monopólio dos Estados em matéria de subjetividade internacional (VALLEJO, 37). As OIs não só favoreceram a humanização, socialização, organização e democratização das relações internacionais, como também contribuíram como um foro privilegiado de "construção" de novos valores, como os direitos humanos, e a incorporação de novos atores, como os indivíduos e as Organizações Não Governamentais (ONG). As OIs criaram ainda uma densa rede de relações ao favorecer a permanência e a

estar das sociedades". Assim, "novos liberais estão comprometidos com políticas de liberalização e internacionalização econômicas que enfraquecem o Estado" (NOGUEIRA, MESSARI, 2005).

${ }^{9}$ A Escola Inglesa traz uma abordagem plurimetodológica das relações internacionais, revelando uma imagem composta por camadas: o sistema internacional; a sociedade internacional e; a sociedade mundial. Hedley Bull, ao explicar as três perspectivas, afirma que um sistema de Estados (ou sistema internacional) é formado quando dois ou mais Estados têm suficiente contato entre eles, e suas decisões possuem impacto suficiente nas decisões dos outros atores. Já, a sociedade internacional por outro lado, existe quando um grupo de Estados, conscientes de certos interesses e valores comuns, formam uma sociedade onde eles se sentem vinculados a um conjunto de regras comuns em suas relações uns com os outros, e participação no funcionamento das instituições comuns (BULL, 2002). Embora os membros da Escola Inglesa atentem à sociedade entre Estados, muitos deles diferem fortemente no entendimento de sua natureza e de sua finalidade (Black; Williams, 2008).

Conjuntura Global, vol. 4 n.3, set./dez., 2015, p. 438-456. 
institucionalização das negociações internacionais e possibilitar a adoção de decisões por maioria. Por fim, as OI favoreceram o desenvolvimento de procedimentos de controle da aplicação das regras internacionais, assim como a definição de regimes internacionais nas mais variadas áreas das Relações Interacionais (VALLEJO, 37).

Dentro dessa visão institucionalista, o conceito de supranacionalidade seria a progressiva transferência de competências dos Estados para as instituições internacionais. Nesse sentido, para o reconhecimento dos fatores que levam à supranacionalização, utilizarse-á de teoria desenvolvida com base na perspectiva institucionalista que, porém, não entra em contradição com a visão cosmopolita. Tais fatores seriam: a) processo decisório, b) órgãos supranacionais, c) direito regional, d) personalidade jurídica (PEREIRA, 2012).

Com relação ao processo decisório (PEREIRA, 2012, p. 87): “a passagem de decisões de unanimidade para maioria representa uma das mais conhecidas formas de supranacionalização". A burocracia internacional também representa uma forma bastante utilizada de supranacionalização. A progressiva participação dos burocratas, em geral em detrimentos dos governos, aparece como uma forma de reforço do caráter supranacional. Do mesmo modo, a criação de cargos e responsabilidades também deve ser visto como um aspecto a ser observado.

Quanto às decisões das organizações, a passagem da recomendação a uma obrigação seguramente constitui uma espécie de supranacionalização. Além disso, quando essa obrigação deixa de atingir somente os Estados-membros da organização e passa a atingir outros atores, como particulares e até Estados não membros, sua supranacionalidade é ainda mais reforçada. Indo mais adiante, essas decisões podem vir a constituir uma espécie de direito comunitário, ou seja, próprio da organização e que prevalece em caso de conflito com normas internas, levando o fenômeno supranacional para ainda mais perto do direito internacional. Outro avanço de supranacionalidade a ser considerado seria a existência de um tribunal próprio que interprete com uniformidade esse direito comunitário. Uma última espécie de reforço à supranacionalidade das decisões parece ser a possibilidade do uso de coerção para o seu cumprimento, com penalidades aos descumpridores das determinações do organismo, que podem variar desde a imposição de multas e suspensão até a expulsão ou o uso da força, entre outras sanções. Por fim, a personalidade jurídica da organização deve ser 
considerada. Desse modo, se há um reforço nessa personalidade e os Estados-membros deixam de agir separadamente e passam a atuar como um só ente (PEREIRA, 2012).

\section{COSMOPOLITISMO E DEMOCRACIA}

O cosmopolitismo, em sua forma moderna, possui algumas premissas básicas: i) os indivíduos (seres humanos) representam as unidades fundamentais da preocupação moral e política; ii) o universalismo, que defende que todos os seres humanos possuem um status moral igual; iii) a justiça mundial, na qual não há isenção das obrigações de respeita ao status moral igual de todos os indivíduos. Ou seja, o cosmopolitismo ressalta a cidadania mundial e o que implica na participação de todos os indivíduos numa comunidade universal de seres humanos, identificados como pessoas individuais e morais. ${ }^{10}$

Para o cosmopolitismo, o indivíduo é o cerne de todas as atenções e preocupações morais, e não o Estado. É um desenvolvimento e reafirmação do liberalismo político, em que todos os indivíduos são iguais, com mesmos direitos e deveres, mas num cenário global. Assim, agir nesse novo mundo, é agir num ambiente sem fronteiras (DUPAS, 2005). Desta forma, o cosmopolitismo busca associar a soberania interna a uma responsabilidade perante os outros, estendendo os direitos e deveres morais a todos os cidadãos do mundo.

Desta forma, a abordagem teórica cosmopolita busca, na atualidade, solucionar os impasses que o avanço da interdependência, da globalização ${ }^{11}$, da democracia, da cidadania e da proteção dos direitos humanos enfrentam. Nesta visão de mundo, a distinção entre nós e os outros (estrangeiros) seria substituída pela construção de um duplo pertencer. 0 cidadão

\footnotetext{
10 Daniel Chernilo (2007, p. 187) conecta as ideias de cosmopolitismo, universalismo e igualdade: "O coração da tradição cosmopolita é inerentemente universal, uma vez que propõe a igualdade fundamental dos seres humanos, independentemente de quaisquer diferenças de classe, gênero, étnica, nacional, religiosa ou cultural. Como programa normativo o cosmopolitismo não pode ser implantado sem um universalismo filosófico básico e deve ser entendido como a consequência normativa necessária de uma reivindicação universalista de conhecimento".

11 As transformações nas relações internacionais apontam para o desenvolvimento de estruturas complementares nos níveis nacional, regional e global. Busca-se, assim, a globalização de padrões de conduta para a humanidade, privilegiando o indivíduo, ou seja, o ser humano. Tais mudanças colocam em xeque o princípio da soberania como organizador básico do sistema internacional (DUPAS, 2005, p. 147). 0 processo da globalização leva em conta a rápida aceleração das interdependências mundiais. Os atores internacionais deveriam desenvolver, neste contexto, "uma soberania cooperativa dos Estados para resolver os problemas globais e que harmonizasse a diversidade e as rivalidades das etnias e das nações" (DUPAS, 2005, p. 146).
} 
seria ao mesmo tempo parte do cosmos e da polis (DUPAS, 2005, p. 227). De maneira complementar, Linklater (2007) observa que, nos novos arranjos políticos do cenário internacional, a soberania, a territorialidade, a cidadania e a nacionalidade já não possuem a mesma importância que antes, ou seja, uma qualidade essencial do Estado. 0 sistema cosmopolita de política geral de segurança busca garantir a proteção não apenas do Estado, mas também dos indivíduos em si, em suas mais variadas associações.

A introdução do direito de bem-estar social surge justamente a partir do reconhecimento de que os indivíduos não podem fazer uso pleno dos seus direitos legais e políticos quando são vítimas de desigualdades estruturais sociais. Assim, busca-se alargar e aprofundar os direitos de cidadania, criando comunidades políticas em que os cuidados para garantir a segurança de todos os membros sejam assegurados.

Sob este prisma crítico de análise, Linklater (2007) defende a emancipação do indivíduo em relação ao Estado-nação, observando a existência de uma cidadania em termos mundiais. Para o autor, o Estado moderno buscou o monopólio do poder sobre cinco diferentes esferas: os instrumentos de controle da violência, o direito de tributação, o direito de solicitar lealdade política de seus cidadãos, assim como o direito de imposição jurídica, e por fim, o direito de representação absoluta no âmbito internacional. 0 objetivo deste projeto foi a criação de comunidades políticas relativamente coesas que salienta as diferenças culturais entre as nações, subordinando os interesses de estrangeiros aos interesses do Estado-nação e negando-lhes a representação e direito de voz aos adversários reais ou potenciais, dentro e fora das fronteiras nacionais.

Para o autor, cada vez mais a aspirações políticas sobre a cidadania não podem ser garantidas por Estados soberanos independentes. Argumenta-se que, com a globalização, os direitos dos cidadãos - sejam eles civis, políticos, sociais ou culturais-, só podem ser garantidos através da criação de uma democracia cosmopolita. Estas estruturas seriam póssoberanas porque os estados não mantêm os seus poderes de monopólio tradicionais. A própria ideia de cidadania requer um movimento deste tipo. Em suma, a cidadania estabelece certos direitos à segurança que os indivíduos e as suas associações têm sido capazes de reclamar contra as respectivas formas estatais típicas, mas não contra os membros das outras sociedades. 
Desta forma, para Linklater, alguns Estados estariam dispostos a colaborar na criação de formas de cidadania transnacional para proteger os direitos legais, políticos, sociais e culturais de todos os membros. Em teoria, eles não estariam simplesmente preocupados com os interesses dos cidadãos, mas se esforçam para fundamentar suas relações externas no compromisso com o diálogo e consentimento, apoiando assim uma comunidade cosmopolita que defende os direitos universais de segurança. Este compromisso poderá significar que eles não se completam em sim mesmos, na consolidação da própria segurança, da identidade e da autonomia. Assim, as sociedades que se dedicam à ampliação das fronteiras da comunidade de segurança podem ser categorizadas como sociedades que entraram na era pós Westfaliana. Sob outro ponto de vista, pode-se dizer que os Estados pós Westfalianos estariam profundamente comprometidos com a erradicação da exclusão, em suas comunidades, e em suas relações externas. Estas sociedades progridem institucionalizando políticas de diálogo e consenso.

Ao se estabelecer alguns pontos de contato entre as visões institucionalista e cosmopolita, pode-se afirmar que ambas aceitam que a supranacionalização ocorreria por meio de organizações internacionais, reconhecendo-se a integração regional como uma etapa em direção à cooperação global. Com relação à democracia, os cosmopolitas pregam a democratização das relações internacionais, que resultaria na criação de um órgão supranacional democrático, aproximando a abordagem cosmopolita à institucionalista. Nesse sentido, o órgão democrático por excelência das instituições internacionais, de acordo com a vertente liberal, seria o Parlamento, que representa a vontade popular.

A democracia, assim, seria vista de modo mais limitado, atendo-se ao controle parlamentar regional, compatível com a visão institucional-cosmopolita. Para os institucionalistas, a supranacionalização tende a ser vista como oposta à democratização, uma vez que distancia o cidadão do centro decisório. Uma das maneiras que os institucionalistas defendem para a democratização das instituições supranacionais seria a instalação de parlamentos diretamente eleitos pelo povo, como é o caso do Parlamento Europeu. Apesar disso, a mera instalação de tal órgão pode não ser suficiente para a democratização. As funções que esse parlamento desempenha são importantes para se avaliar o controle democrático em alguma área. Desse modo, uma vez esclarecidos e compatibilizados os 
conceitos de supranacionalidade e democracia, passa-se à aplicação dessas teorizações aos casos concretos, verificando-se o reforço das instituições regionais (especialmente parlamentos) em matéria de segurança e defesa.

\section{UNIÃO EUROPEIA}

A União Europeia pode ser considerada um dos maiores exemplos de organização supranacional. Apesar disso, no âmbito da segurança e defesa, o bloco parece apresentar menos características supranacionais do que no campo econômico-comercial. Mais especificamente, a política de segurança europeia é chamada de Política Externa e de Segurança Comum (PESC), criada pelo Tratado de Maastricht, assinado em 1992, consolidando o bloco com a denominação União Europeia e seu aspecto de defesa (FERREIRA-PEREIRA, 2005). Com relação à estrutura organizacional, o artigo 4o. do Tratado de Roma, assinado em 1957, criou a Comunidade Econômica Europeia (também conhecida como Comunidade Europeia) e suas quatro instituições fundamentais: Parlamento Europeu, Conselho ${ }^{12}$, Comissão e Tribunal de Justiça.

Enquanto o Conselho é composto pelos ministros dos Estados-membros, em geral da pasta de Relações Exteriores, o Parlamento é composto pelos deputados eleitos diretamente pelos europeus, proporcionalmente à população de cada país. Desse modo, o Conselho seria o principal componente do poder legislativo do processo de integração, função que ao longo do processo de evolução comunitária passou a compartilhar cada vez mais com o Parlamento. A Comissão, por sua vez, seria o órgão supranacional por excelência e poder executivo do bloco (PEREIRA, 2012).

O Conselho, juntamente com o Parlamento e a Comissão formam o chamado triângulo institucional e são os órgãos responsáveis pelo processo legislativo do bloco, produzindo normas obrigatórias para todos os membros. Esse conjunto de normas forma uma espécie de

\footnotetext{
12 Vale ressaltar que aqui se utiliza o termo "Conselho" para referir-se ao Conselho da União Europeia, também conhecido como Conselho de Ministros, uma vez que tal prática é adotada largamente pelos acadêmicos, burocratas e diplomatas. Tal instituição não deve ser confundida com o Conselho Europeu, órgão da UE que reúne os líderes (chefes de Estado e de governo) europeus. Também deve ser diferenciado do Conselho da Europa, organização internacional distinta da UE.
} 
"bagagem" ou "herança", conhecida como acquis communautaire, que deve ser aceita por todos os Estados que venham a aderir ao bloco e é o principal objeto das negociações de adesão de novos membros. No âmbito da PESC, essas normas também são conhecidas mais especificamente como acquis politique. Assim como os tratados, as normas produzidas pelas instituições europeias também fazem parte do aquis comunitário, o qual procede a uma limitação progressiva (podendo ser encarada como supranacionalização) da soberania dos Estados-membros (PEREIRA, 2012).

A participação de Parlamento Europeu pode ser definida como marginal. A decisão no âmbito da PESC é tomada pelos Estados-membros reunidos no Conselho em geral por unanimidade, em reuniões presididas por um funcionário público internacional, o chamado Alto-Representante, que é o chefe da diplomacia europeia. Sua implementação é realizada em conjunto pela Comissão Europeia e os Estados-membros. Além disso, o Parlamento pode emitir recomendações a respeito dessa política. 0 Tratado de Lisboa, em vigor desde 2009, última grande reforma da UE, realizou uma pequena supranacionalização no âmbito da PESC. As principais mudanças foram: a) nomeação de um Presidente do Conselho Europeu13; b) novas funções do Alto Representante14; c) criação de um serviço diplomático europeu15; d) atribuição de personalidade jurídica à UE16. 0 Conselho Europeu, composto pelos chefes de Estado e governo, surge como uma prática e acaba se institucionalizando com o referido tratado. 0 controle democrático se dá justamente no órgão supranacional, que é a Comissão Europeia. A nomeação da Comissão deve ser aprovada pelo Parlamento. Desse modo, percebe-se que os Estados resistem em ceder poderes nessa área à UE, justamente onde o

\footnotetext{
${ }^{13}$ Anteriormente, a Presidência do Conselho Europeu era rotativa semestralmente entre os Chefes de Estado e governo dos Estados-membros, deixando que interesses dos Estados que exerciam o cargo se sobrepusessem aos da União.

14 O Alto Representante ocupava, até então, a Secretaria-Geral do Conselho, que reúne os Ministros de Relações Exteriores dos países do bloco. A Presidência desse Conselho era exercida semestralmente pelos Ministros, e agora passa a ser função do Alto Representante. Além disso, o Alto Representante passa a exercer concomitantemente o cargo de Comissário de Relações Externas, que já existia. Na natimorta Constituição Europeia, esse novo cargo era chamado de Ministro de Relações Exteriores.

15 Oficialmente chamado de Serviço Europeu de Ação Externa, chefiado pelo Alto Representante, conhecido assim como Chefe da diplomacia europeia

${ }^{16}$ A falta de personalidade da UE fazia com que o Estado que exercia a Presidência assinasse acordos e representasse o bloco em reuniões e aparições internacionais. Em algumas questões, a Comissão representava a UE. Com a atribuição, o Alto Representante recebeu todas as competências e as representações da Comissão no exterior foram convertidas em delegações da UE, chefiadas por Embaixadores, subordinados ao Alto Representante.
} 
Parlamento exerce o controle democrático. Assim, percebe-se que o controle democrático do Parlamento Europeu ocorre justamente quando há mais supranacionalização, sendo os dois movimentos não contraditórios, mas no mesmo sentido, diferentemente do que se supunha inicialmente. Apesar disso, a UE gradativamente foi tendo sua personalidade reconhecida por meio de delegações em vários países (PEREIRA, 2012).

Além disso, a UE vem participando em foros de discussão internacional como o G-7, o G-20 e a própria ONU. No âmbito mais específico da segurança, o bloco enviou missões civis e militares ao continente africano e europeu, sendo a mais relevante a EULEX, para a estabilização do Kosovo. Ademais, assumiu todas as funções da União da Europa Ocidental (UEO), principal organização militar exclusivamente europeia (PEREIRA, 2012). Tudo isso comprova que a UE vêm sendo cada vez mais reconhecida como um ator de relevância no âmbito da segurança global.

Desse modo, constata-se que a UE vem gradativamente adquirindo aspectos supranacionais em sua política de segurança, ainda que de maneira tímida. Com relação à democratização, nota-se que, de forma incipiente, o Parlamento Europeu encontra formas de aproximar a população do bloco, fazendo com que os anseios cosmopolitas sejam, pelo menos parcialmente, atendidos. Desse modo, apesar de alguns assuntos em matéria de segurança e defesa parecerem mais distantes dos cidadãos por serem decididos em Bruxelas, e não em suas capitais nacionais, a população mantém certo controle do que é discutido no âmbito da organização por meio de parlamentares diretamente eleitos.

\section{UNASUL}

Diferentemente da UE, a UNASUL se aproxima mais de um instrumento de cooperação intergovernamental regional que dos padrões clássicos de integração supranacional A UNASUL possui uma estrutura permanente, cuja sede principal fica em Quito, no Equador, dando-lhe um aspecto institucional. A organização foi constituída em 2008 com a publicação de seu Tratado Constitutivo, mas que só em vigor em março de 2011, quando se cumpriu a condição de ao menos nove países o ratificarem (UNASUR, 2015). 
Com a ratificação dos doze países da região, foram propostas diversas políticas públicas nos mais diversos setores: integração estrutural, energética, de segurança, saúde, educação, cultura, ciência, tecnologia, dentre tantas outras. A UNASUL, assim, é composta de quatro órgãos: o Conselho de Chefas e Chefes de Estado; o Conselho de Ministras e Ministros das Relações Exteriores; o Conselho de Delegadas e Delegados; e a Secretaria Geral. Destaca-se o fato de que o Secretário-Geral não poderá ser sucedido por uma pessoa da mesma nacionalidade. ${ }^{17}$ O Secretário-Geral será o representante legal da Secretaria Geral. Na escolha dos membros do Secretariado Geral para a representação equitativa entre os EstadosMembros, leva-se em conta, sempre que possível, critérios de gênero, língua, etnia e outros (UNASUR, 2015).

Dessa maneira, a organização é colocada sob o comando de um Secretário-Geral com um mandato de dois anos. Apesar disso, a intergovernamentalidade prevalece, especialmente com a rotatividade na Presidência pro tempore, passada para cada país-membro a cada seis meses.

A Organização possui ainda doze órgãos setoriais ${ }^{18}$. Para os fins aqui propostos, destaca-se que o principal órgão no âmbito da segurança é o Conselho de Defesa SulAmericano (CDS). 0 CDS foi criado em 2008, reúne os Ministros da Defesa dos doze países do bloco duas vezes por ano, sob a presidência do ministro do Estado que exerce a presidência. As decisões são tomadas por consenso dos Ministros da Defesa dos Estados-membros, em reunião presidida pelo ministro do país que estiver exercendo a presidência rotativa do bloco. Além disso, o referido órgão não dispõe de pessoal próprio, contando com os funcionários do país na Presidência. O CDS também nunca criou missões internacionais, o que reforça o caráter eminente intergovernamental da UNASUL (UNASUR, 2015).

\footnotetext{
17 Durante o desempenho de seus deveres, o Secretário-Geral e o pessoal do Secretariado não solicitarão nem receberão instruções de qualquer governo ou entidade que não seja a UNASUL, e devem abster-se de praticar qualquer ato incompatível com sua condição de funcionários internacionais, responsáveis só a esta organização internacional.

${ }_{18}$ Conselho Energético Sul-Americano; Conselho de Defesa Sul-Americano; Conselho de Saúde Sul-Americano; Conselho Sul-Americano para o Desenvolvimento Social; Infraestrutura Sul-Americana e Conselho de Planejamento; Conselho Sul-Americano sobre o Problema Mundial das Drogas; Conselho Sul-Americano de Economia e Finanças; Conselho Eleitoral da UNASUL; Conselho Sul-Americano de Educação; Conselho SulAmericano da Cultura; Conselho Sul-Americano de Ciência, Tecnologia e Inovação; Conselho Sul-Americano sobre Segurança Cidadã, Justiça e Coordenação da Ação contra a Criminalidade Organizada Transnacional.
} 
Os objetivos gerais do CDS são: i) consolidar a América do Sul como una zona de paz, base para a estabilidade democrática e o desenvolvimento de seus povos, contribuindo assim para a consolidação da Paz mundial; ii) construir uma identidade sul-americana em matéria de defesa, que leve em conta as características regionais, sub-regionais e nacionais, que contribua no fortalecimento da unidade América Latina e Caribe; iii) lograr consensos para fortalecer a cooperação regional em matéria de defesa. Como pode ser visto o Estatuto do CDS não menciona a integração como objetivo específico (art. $4^{\circ}$ ). Contudo, reafirma os princípios tradicionais de soberania, as instituições democráticas, os direitos humanos, a convivência pacífica entre os povos, a solução pacífica de controvérsias. Nota-se, portanto, que os desafios do CDS perpassam por questões que extrapolam a esfera de defesa, englobando as diferentes percepções de cada ator da região sobre ameaça, defesa e segurança (UNASUR, 2015).

Como ações concretas que buscam consolidar e avança na institucionalidade do CDS, destaca-se a criação do Centro de Estudos Estratégicos de Defesa (CEED), proposta Argentina presente no Plano de Ação 2010-2011. Localizado em Buenos Aires, o CEED tem como objetivos: a) Contribuir, mediante análises permanentes, identificação de desafios, fatores de risco e ameaça, oportunidades e cenários relevantes para a defesa e a segurança regional e mundial, tanto no presente quanto no mediano e longo prazo; b) Promover a construção de uma visão compartilhada que possibilite a abordagem comum em matéria de defesa e segurança regional, dos desafios, fatores de risco e ameaça, oportunidades e cenários previamente identificados, conforme os princípios e objetivos expostos no Tratado Constitutivo da UNASUL e no Estatuto do CDS; c) Contribuir na identificação de enfoques conceituais e lineamentos básicos comuns que permitam a articulação de políticas em termo de defesa e segurança regional (Estatuto do Centro de Estudos Estratégicos de Defesa do CDS, artigo 3). Além das iniciativas supracitadas, o CEED realiza cursos e seminários, forma grupos de trabalho para discutir variados aspectos e a implantação de um sistema para medir os gastos militares dos países da região (UNASUR, 2015).

Os Ministros da Defesa também aprovaram a criação da Escola de Defesa SulAmericana (ESUDE). Sua primeira reunião em 2014 resultou em uma proposta de Estatuto e Regulamentos que será encaminhada à Instância Executiva para apreciação e aprovação. De 
acordo com Antônio Jorge Ramalho da Rocha, Secretário-Geral da Escola, a "ESUDE iniciou, neste segundo semestre de 2015, suas atividades. Sua missão é construir confiança mútua, ampliar a transparência dos sistemas de defesa na região e contribuir para consolidar a cooperação internacional no campo da defesa" (ROCHA, 2015, p. 1).

Com formato descentralizado, a Esude será mais uma estrutura foi criada no âmbito da segurança e defesa da UNASUL, contribuindo para uma gradual institucionalização e supranacionalização do bloco. Assim, pequenas supranacionalizações ocorreram com o estabelecimento do Centro de Estudos e da Escola. Para Rocha, ainda "A observação da experiência europeia realçou a imprudência de deixar as dimensões de política externa e defesa para o final do processo: os objetivos finais podem frustrar-se caso não se enfrentem os temas sensíveis desde o início" (ROCHA, 2015, p. 2).

A UNASUL também se responsabiliza com a democratização. 0 Protocolo adicional ao Tratado Constitutivo da UNASUL sobre compromisso com a democracia, assinado em 26 de novembro de 2010 em Georgetown, Guiana, entrou em vigor em 19 de março de 2014, 30 dias após o nono país do bloco ratifica-lo. O Protocolo corrobora com políticas regionais já existentes na defesa ativa dos regimes democráticos regionais. No entanto, "o Protocolo, mesmo que tenha sido capaz de prever medidas drásticas de preservação dos regimes democráticos na região, não conseguiu superar as barreiras do intergovernamentalismo e da obrigatoriedade de se tomar decisões por consenso" (PAGLIARI, PERGHER, 2015, p. 323).

Na Declaração de Cochabamba, os países firmaram o princípio de que, tanto a democracia quanto o pluralismo seriam fundamentais para consolidar uma integração sem ditaduras e respeitosa aos direitos humanos. Dessa forma é que propõe alianças estratégicas baseadas, dentre outros, no compromisso democrático (UNASUR, 2015). Por sua vez, o Tratado Constitutivo ratifica a democracia como base da integração e salienta o princípio segundo o qual "a vigência das instituições democráticas e o respeito aos direitos humanos". Destaca-se ainda o fato que o Tratado Constitutivo prevê ainda a criação de um Parlamento da União de Nações Sul-Americanas. Uma vez criado, o Parlamento Sul-Americano, terá sede em Cochabamba, Bolívia. ${ }^{19}$

19 No Tratado existem ainda um Artigo Transitório dispõe sobre uma Comissão Especial com o objetivo de elaborar um Projeto de Protocolo Adicional que estabelecerá o Parlamento Sul-Americano:"Artigo Transitório: 
Porém, a Cláusula Democrática da UNASUL ${ }^{20}$ traz possibilitadas duras medidas caso quaisquer dos Estados Membros da UNASUL passem por rupturas democráticas ou haja evidências de ameaças de ruptura. Este mecanismo pode reduzir as chances de um membro da organização passar por uma brusca ruptura democrática. No entanto, no texto da cláusula "não são apontados meios práticos que levarão à aplicação dessas medidas em caso concreto. Assim, entende-se que falta operacionalidade prática aos procedimentos de segurança democrática" (PAGLIARI, PERGHER, 2015, p. 324).

Ainda segundo os autores, no "campo legislativo está ainda muito distante da efetiva aplicação ao caso concreto. Além disso, o processo de decisão intergovernamental, que depende da vontade unânime dos Estados-membros, também dificulta a efetividade da instituição". Mas, reconhecem-se os avanços institucionais, ainda que meramente textuais. 0 "papel desempenhado pelo Protocolo Adicional sobre a Democracia, no âmbito da UNASUL, certamente representa grande avanço institucional na defesa da democracia e da paz na região" (PAGLIARI, PERGHER, 2015, p. 324). Entretanto, eventos como a crise democrática no Paraguai em 2012 "demonstram que as ações formalmente garantidas pelo Protocolo ainda estão muito longe do que efetivamente pode ser feito em momentos de crise" (PAGLIARI, PERGHER, 2015, p. 324).

Desse modo, a partir de uma visão cosmopolita, percebe-se que a UNASUL possui pretensões no sentido de democratizar o processo de integração, mas isso ainda precisa se converter em ações. Por outro lado, em uma perspectiva institucionalista, contata-se uma contínua e gradual supranacionalização do bloco, especialmente na área de segurança, como demonstram a criação do CDS, do Centro de Estudos e da Escola de Defesa. Cumpre ressaltar que isso ocorre justamente na área em que os Estados tradicionalmente mais resistem em cooperar, o que pode representar um grande avanço na direção de maior aproximação e construção de confiança entre os Estados da América do Sul.

\footnotetext{
As Partes acordam designar uma Comissão Especial, que será coordenada pelo Conselho de Delegadas e Delegados e será integrada por representantes dos Parlamentos Nacionais, Sub-regionais e Regionais com o objetivo de elaborar um Projeto de Protocolo Adicional que será considerado na IV Cúpula de Chefas e Chefes de Estado e de Governo. Essa Comissão se reunirá na cidade de Cochabamba. Esse Protocolo Adicional estabelecerá a composição, as atribuições e o funcionamento do Parlamento Sul-Americano".

${ }^{20}$ Como tem sido conhecido o Protocolo Adicional ao Tratado Constitutivo da UNASUL sobre Compromisso com a Democracia
} 
Apesar disso, o que ocorre na região parece cada vez mais distanciar o cidadão dos assuntos de segurança e defesa. Primeiro, por meio da supranacionalização, essa área se afasta da população, pois parte das discussões passa a ser no âmbito da organização e não mais nas capitais nacionais. Em segundo lugar, a UNASUL carece de órgãos democráticos, uma vez que seu parlamento, apesar de previsto, ainda não foi devidamente implementado. Assim, temas relacionados à segurança internacional, tradicionalmente mantidos afastados da população, na América do Sul parecem sofrer um distanciamento ainda maior por meio da UNASUL que, além de ter recebido atribuições nessa área, não permite o controle democrático do cidadão em suas instituições.

\section{CONSIDERAÇÕES FINAIS}

O presente artigo objetivou realizar uma análise comparativa entre os processos de integração regional no âmbito da segurança na Europa e na América do Sul, a partir de perspectivas institucionalistas e cosmopolitas. No escopo institucionalista, foi destacado o conceito de supranacionalidade, constatado pela transferência de competências dos Estados às organizações internacionais. Nesse âmbito, ficou demonstrado que a União Europeia se encontra, em geral, em um estágio mais avançado de integração na área de segurança que a UNASUL. Apesar disso, essa parece ser uma área prioritária para o bloco sul-americano, enquanto que no âmbito europeu foi por muito tempo relegada a um segundo plano.

Utilizando-se de lentes cosmopolitas, buscou-se identificar a democratização da UNASUL e da UE, constatando-se que os europeus têm conseguido, mesmo de que forma tímida, traduzir seus anseios democráticos em realidade, especialmente por meio do Parlamento Europeu. Os sul-americanos, apesar de terem boas intenções nesse sentido, com a previsão de um parlamento regional, ainda não se demonstraram capazes de implementálas. A "cláusula democrática", embora pareça aproximar o bloco do cosmopolitismo, não facilita o acesso da população às decisões regionais. Indo além, percebe-se que, no caso da

UNASUL, assuntos já afastados do povo como segurança e defesa tornaram-se ainda mais distantes, tanto pela supranacionalização do tema no âmbito do organismo regional, como pela ausência de controles democráticos institucionalizados. 
Apesar disso, percebe-se que os ideais cosmopolitas e institucionalistas ainda estão muito distantes em ambos os blocos, tanto em relação à democratização como em relação à supranacionalização, fazendo com que os Estados continuem a manter, em grande medida, o controle em termos de segurança. Assim, ao mesmo tempo em que as abordagens intergovernamentais que enfatizam o papel dos Estados nas relações internacionais continuam relevantes para a compreensão da cooperação em torno da segurança em ambas as regiões, a crescente supranacionalização de UNASUL e da UE vem tornando a visão institucionalista cada vez mais apropriada para a análise dessas realidades. A democratização institucional, por outro lado, constata-se apenas no processo europeu, fazendo com que a teoria cosmopolita, apesar de vir se tornando adequada à análise da UE, ainda careça de força explicativa e represente uma crítica em relação à UNASUL.

\section{REFERÊNCIAS}

ABDUL-HAK, Ana Patrícia Neves Tanaka. O CONSELHO DE DEFESA SUL-AMERICANO (CDS) Objetivos e interesses do Brasil. Fundação Alexandre Gusmão. Brasília, 2013.

BLACK, David R.; WILIAMS, Paul D.. DARFUR'S CHALLENGE TO INTERNATIONAL SOCIETY. Canadian International Council, 2008

BROWN, C.. Sovereignty, Rights and Justice: International political theory today. Cambridge: Polity Press, 2002.

BULL, H. A Sociedade Anárquica. Brasília: Editora Universidade de Brasília. 2002

CAMARGO, Alan G. Democratizando a América Latina? A promoção de democracia por meio do Regime Democrático Interamericano. Brasília: Dissertação de mestrado em Relações Internacionais. UnB, 2013.

CARRILLO SALCEDO, Juan Antonio. Soberanía de los Estado y Derecho Humanos em Derecho Internacional contemporáneo. Tecnos, Madrid, 2001.

CLARK, Ian. Legitimacy in International Society. Oxford: Oxford UP, 2005

DUNNE, Tim, 'The New Agenda' in Alex J. Bellamy (ed.), International Society and Its Critics .Oxford: Oxford University Press, 2004.

DUPAS, Gilberto. Atores e Poderes na Nova Ordem Global. UNESP, 2005.

FERREIRA-PEREIRA, Laura C. A Europa da defesa: o fim do limbo. Nação e Defesa. Lisboa, $\mathrm{n}$. 110 - 3a série, p. 87-127. Primavera de 2005. 
GLEDITSCH, Nils Petter; SOYSA, Indra. The Liberal Globalist Case, In: Björn Hettne and Bertil Odén, ed., Global Governance in the 21st Century: Alternative Perspectives on World Order. Stockholm: Almkvist \& Wiksel International, 2002.

HOLSTI, Kalevi J.. The coming chaos? Armed conflict in the world's periphery. In: T. V. Paul \& John A. Hall, eds, International Order and the Future of World Politics. Cambridge: Cambridge University Press, 1999.

JACKSON, R., Sovereignty: Evolution of an idea. Cambridge: Polity Press, 2007.

LIDEN, K. (2006) Whose Peace? Which Peace? On the Political Architecture of Liberal Peacebuilding. International Peace Research Institute, Oslo (PRIO). Disponível em: http://www.st-andrews.ac.uk/intrel/media/Liden_whose_peace.pdf. Acesso em: 27/07/12.

LINDGREN ALVES, José Augusto. Os direitos humanos como tema global. 2a ed. São Paulo: Paz e Terra, 2003. . Os direitos humanos na pós-modernidade. São Paulo: Perspectiva, 2005.

LINKLATER, Andrew. The transformation of political community Towards 'A Cosmopolitan System of General Political Security'. In: Conference, "Culture, Identity and Global Security", Yourk University, Toronto, Canada, 1997. 2007.

Critical Theory and World Politics Citizenship, sovereignty and humanity. Routledge,

PAGLIARI, Graciela C.; PERGHER, H. Democracia e Guerra na América do Sul - os avanços e os limites da defesa da democracia na busca pela paz. Coleção Meira Mattos - Revista das Ciências Militares, v. 9, p. 321-331, 2015.

PEREIRA, Demetrius Cesário. A Política Externa e de Segurança Comum da União Europeia após o Tratado de Lisboa: a caminho da supranacionalidade? São Paulo. Tese de doutorado em Ciência Política. USP, 2012.

PIRES. Norma da Silva Venancio. Parlamentos Regionais e o Processo de Integração. Instituto Universitário de Pesquisas do Rio de Janeiro. Centro de Formação, Treinamento e Aperfeiçoamento da Câmara dos Deputados. Rio de Janeiro, 2009.

ROCHA, Antonio Jorge Ramalho da. A Escola de Defesa Sul-Americana. Disponível em: http://mundorama.net/2015/09/02/a-escola-de-defesa-da-america-do-sul-por-antoniojorge-ramalho/ . Acesso em 18/11/2015.

SÁ GUIMARÃES, Feliciano. O Debate entre Comunitaristas e Cosmopolitas e as Teorias de Relações Internacionais: Rawls como uma Via Média. CONTEXTO INTERNACIONAL. Rio de Janeiro, vol. 30, no 3, setembro/dezembro 2008.

SILVEIRA, Rui Monarca da. Pensamento Brasileiro sobre defesa e Segurança. In: ALMEIDA PINTO, J.R. de; RAMALHO DA ROCHA; A.J.; DORING PINHO DA SILVA, R. (org.) Reflexões sobre defesa e segurança : uma estratégia para o Brasil. Ministério da Defesa, Secretaria de Estudos e de Cooperação. Brasília, 2004.

SOUSA, Fernando de. (org.). Dicionário de Relações Internacionais. Edições Afrontamento, CEPESE e autores. Portugal, 2005. 
UNASUR. Unión de Naciones Suramericanas. Disponível em http://www.unasursg.org . Acesso em 18/11/2015.

VALLEJO, Manuel Diez de Valesco. Las Organizaciones Internacionales. 13.ed. Madrid: Tecnos, 1998. 